\title{
Impact of downstream effects of glucocorticoid receptor dysfunction on organ function in critical illness-associated systemic inflammation
}

\author{
Martin Wepler ${ }^{1,2^{*}}$, Jonathan M. Preuss ${ }^{3}$, Tamara Merz ${ }^{1}$, Oscar McCook ${ }^{1}$, Peter Radermacher ${ }^{1}$, \\ Jan P. Tuckermann ${ }^{3}$ and Sabine Vettorazzi ${ }^{3}$
}

From 4th International Symposium on Acute Pulmonary Injury and Translational Research - INSPIRES 2019

Dresden, Germany. 25-26 November 2019

\author{
*Correspondence: martin.wepler@ \\ uni-ulm.de \\ ${ }^{1}$ Institute for Anesthesiological \\ Pathophysiology and Process \\ Engineering, University Hospital \\ Ulm, Ulm, Germany \\ 2Department of Anesthesia, \\ University Hospital Ulm, Ulm, \\ Germany \\ Full list of author information is \\ available at the end of the article
}

\begin{abstract}
Glucocorticoids (GCs) are stress hormones that regulate developmental and physiological processes and are among the most potent anti-inflammatory drugs to suppress chronic and acute inflammation. GCs act through the glucocorticoid receptor (GR), a ubiquitously expressed ligand-activated transcription factor, which translocates into the nucleus and can act via two different modes, as a GR monomer or as a GR dimer. These two modes of action are not clearly differentiated in practice and may lead to completely different therapeutic outcomes. Detailed aspects of GR mechanisms are often not taken into account when GCs are used in different clinical scenarios. Patients, with critical illness-related corticosteroid insufficiency, treated with natural or synthetic GCs are still missing a clearly defined therapeutic strategy. This review discusses the different modes of GR function and its importance on organ function in vivo.

Keywords: Glucocorticoid receptor, Dysfunction, Monomer, Dimer, Systemic inflammation, Mouse models, Organ function
\end{abstract}

\section{Background}

Glucocorticoids (GCs) belong to the steroid hormones and are derived from cholesterol through different intermediates. They are released by the adrenal glands, in a circadian rhythm, and play a crucial role in the adult physiology: immune function, glucose metabolism, and blood pressure regulation. This GC homeostasis (circadian rhythm) could be challenged and affected by acute and chronic stress and systemic inflammation. The GCs have multifaceted actions and therefore an impact on metabolism, bone, and immune system. The GCs-as anti-inflammatory and immunosuppressant drug_are already used since 1948 by Philip Hench and Edward

(c) The Author(s). 2020 Open Access This article is licensed under a Creative Commons Attribution 4.0 International License, which permits use, sharing, adaptation, distribution and reproduction in any medium or format, as long as you give appropriate credit to the original author(s) and the source, provide a link to the Creative Commons licence, and indicate if changes were made. The images or other third party material in this article are included in the article's Creative Commons licence, unless indicated otherwise in a credit line to the material. If material is not included in the article's Creative Commons licence and your intended use is not permitted by statutory regulation or exceeds the permitted use, you will need to obtain permission directly from the copyright holder. To view a copy of this licence, visit http://creativecommons.org/licenses/by/4.0/. 
Kendall to treat patients with rheumatoid arthritis and efficiently reduce the inflammatory effects [1]. This was awarded with the Nobel Prize in 1950 [2]. Until present, synthetic GCs are indispensable for the treatment of inflammatory diseases.

\section{Importance of glucocorticoids in critical illness}

Critical illness represents severe acute stress and is therefore often accompanied by high levels of GCs (cortisol in humans and corticosterone in rodents, Fig. 1). This observation has traditionally been attributed to stress-induced activation of the hypothalamic-pituitary-adrenal (HPA) axis and the subsquently increased corticotropin-driven GC production (Fig. 1, [3]). Furthermore, suppressed expression and activity of cortisol-metabolizing enzymes lead to a reduced cortisol breakdown, which also contributes to hypercortisolemia and, hence, adrenocorticotropin suppression [4]. However, in patients with critical illness, the systemic availability of cortisol may be not high enough to face the stress induced by the illness and, together with the hypercortisolemia-induced corticotropin suppression, present as "critical-illness-related corticosteroid insufficiency" (CIRCI). Besides, patients with CIRCI often present "corticosteroid resistance", which indicates CIRCI as a relative adrenal failure, because the cortisol levels are high but do not induce their regular effects within this corticosteroid resistance $[5,6]$. In critically ill patients with sepsis, the excessive cytokine production may further suppress later adrenocorticotropin hormone synthesis [7, 8] and the cortisol response to exogenous adrenocorticotropin hormones $[9,10]$, thereby aggravate CIRCI. However, there is still an ongoing discussion about GC therapy in critical

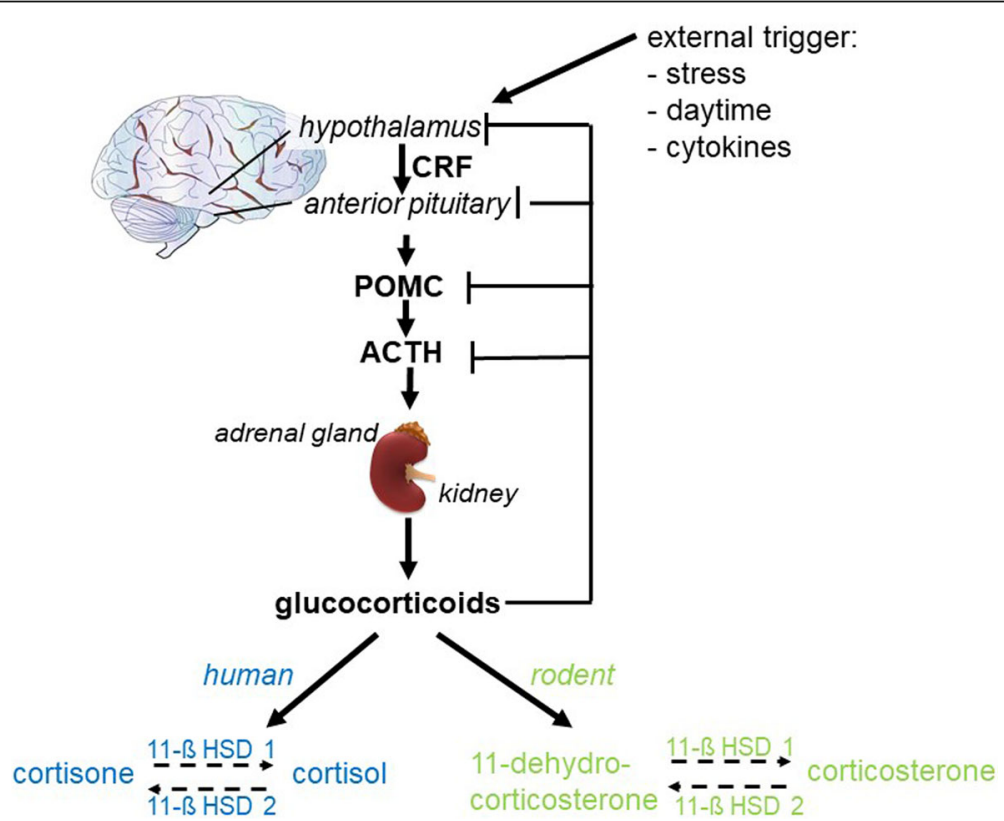

Fig. 1 After the activation of the hypothalamus by external triggers, corticotropin-releasing factor (CRF) acts on the anterior pituitary to release proopiomelanocortin (POMC), which in turn is a proteolytic cleaved in adrenocorticotropic hormone (ACTH) and activates the production of enzymes for the corticosteroid synthesis in the adrenal glands. Glucocorticoids act in a negative feedback mechanism to regulate their own production. In humans, cortisone is converted by $11-\beta$-hydroxysteroid-dehydrogenase-1 (11 $\beta$-HSD1) to cortisol and vice versa by $11 \beta-H S D 2$. In rodents, the 11-dehydrocorticosterone is converted to

corticosterone and vice versa 
illness, especially in acute respiratory distress syndrome (ARDS) and sepsis. The lack of clarity of the effects of GC treatment in critical illness may also be related to different effects and states of glucocortiocid receptor (GR) function, because GCs mainly mediate their effects by binding to the GR. This review will focus on the role of GR fuction in criticall ilness-associated systemic inflammation and the downstream effects on organ function.

\section{The endogenous glucocorticoid biosynthesis and importance in homeostasis}

Glucocorticoids (GCs) belong to the steroid hormones, which are derived from cholesterol through different intermediates like progesterone. GCs have a crucial role in physiology (immune function, glucose metabolism, and blood pressure regulation), but also during development: GCs are important for the differentiation of chromaffin cells and bone integrity [11-14] and, moreover, for lung maturation [13].

The synthesis of steroids takes place in the mitochondrium and the endoplasmic reticulum of steroid-synthesizing cells. The rate-limiting enzymes of the steroid synthesis are cholesterol esterase, steroidogenic acute regulatory protein (Star), and cytochrome P450 [15]. GCs are produced in the adrenal glands, in the zonae fasciculata which is the intermediate part of the adrenal glands. GC production is mediated by a hierarchical hormonal signaling that is composed of the hypothalamus, the pituitary, and the adrenal, designated as the HPA axis. Upon input of centers that maintain the circadian rhythm, the occurrence of acute stress, or systemic inflammation, the hypothalamus releases the corticotropin-releasing factor (CRF). CRF acts on the adenohypophysis resulting in the synthesis of proopiomelanocortin (POMC) [16]. POMC is proteolytically cleaved into adrenocorticotropic hormone (ACTH) and activates the production of enzymes for the corticosteroid synthesis in the adrenal cortex (Fig. 1). The concentration of GCs is regulated by a negative feedback mechanism: high levels of GCs suppress POMC and CRF expression and thereby shut down the central synthesis of GCs. This is the underlying mechanism for the ultradian and diurnal rhythm of corticosterone in rodents and cortisol in humans. Once delivered into the blood, almost 90\% of the hydrophobic released GCs are bound, transported, distributed, and released into the cell with the help of corticosteroid-binding globulin (CBG), also known as transcortin [17]. Within the cells, the $11 \beta$-hydroxysteroid dehydrogenase 1 and 2 (11ß-

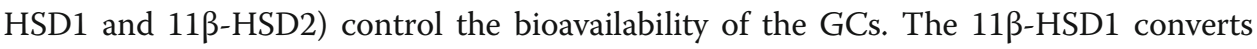
the inactive into the active form (human: cortisone into cortisol; rodents: 11dehydrocorticosterone into corticosterone). Conversely, the active form (human: cortisol; rodents: corticosterone) is oxidized by $11 \beta-H S D 2$ to the inactive form (Fig. 1, [18]). Due to the differential expression of $11 \beta-H S D 1$ (which amplifies GC concentrations) or/and 11ß-HSD2 (which reduces GC concentrations), GC sensitivity can influence a metabolic syndrome caused by obesity and/or insulin resistance [19, 20].

\section{Molecular mechanims of GC action: transcactivation transrepression}

GCs act via two receptors, the high-affinity mineralocorticoid receptor (MR) and the low-affinity glucocorticoid receptor (GR). However, MR expression seems to be more restricted to distinct tissues, in some of which GCs are inactivated by 11 $\beta$-HSD2. Since the GR is more widespread, the majority of GC action is indeed mediated by the GR. The GR is a nuclear receptor that resides in the cytoplasm complexed with 
immunophilins (Fkbp5), heat shock proteins (Hsp70, Hsp90, p23), and chaperone molecules in the absence of ligand [21-23]. After binding of the ligand (e.g., GCs) to the GR, a conformational change together with the Hsp allows a proper folding of the GR. The major fraction of the GR molecules translocates into the nucleus after binding to the ligand and directly acts on gene regulation. To this end, the immunophilins and Hsps must dissociate to allow interaction of the GR with the protein import machinery. In the nucleus, the ligand-bound GR can either act as a single molecule (monomer) or as a homodimer (2 GR molecules, Fig. 2).

As a dimer, the GR binds to GR binding sites (GBS). The classical sequence motif of the GBS is the GR response element (GRE) that is comprised of a palindromic DNA sequence (GGAACAnnnTGTTCT), which is separated by a 3-base pair spacer (n), but also display a certain degree of degeneration of the consensus sequence $[24,25]$. The DNA-bound GR homodimer recruits co-regulatory molecules by its $\mathrm{N}$-terminal and $\mathrm{C}$-terminal transactivation functions that lead to chromatin remodeling, a prerequisite to induce transcription of GC-regulated genes. Genome-wide analyses revealed that tissue-specific transcription factors poise the chromatin for tissue-selective GR binding to GBS that lead to a tissue-specific hormone response [26-30].

The monomer GR either directly binds to DNA at the so-called half-GREs (1/2 GRE) that contain one half of the palindromic sequence of the classical GRE or, alternatively, interacts with other transcription factors bound to their responsive elements [26, 31]. Among these, many were identified as transcription factors involved in cytokine regulation and regulation of other pro-inflammatory mediators. Of note, just recently, the GR was described to act as a tetramer, but the significance and physiological relevance of this finding still needs further investigation [32]. This shows that the GR biology is an

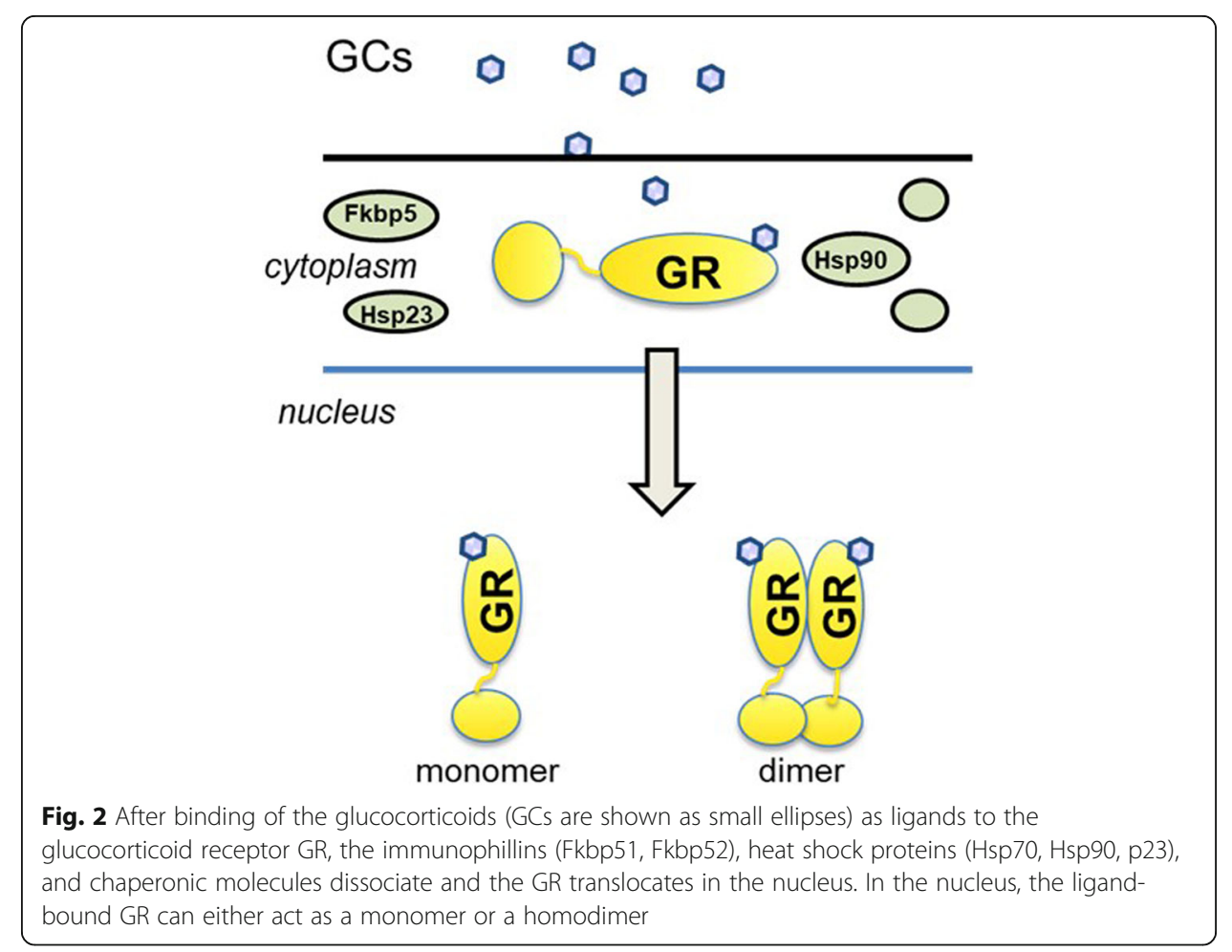


important component and mediator of the GC effects that must be taken into consideration.

\section{The (almost) failed question of dissociating GR ligands}

For GC therapy, a fundamental question is how to differentiate side effects from beneficial effects, in other words, to define therapeutic windows for immune modulatory functions, to allow a safer GC therapy, by either reducing side effects or increasing the efficacy. The discovery that GR acts as a dimer or as a monomer provoked great hopes to develop dissociating ligands that could promote beneficial effects while avoiding GRmediated side effects [33]. In the pre-genome era, when only a limited set of GR target genes were known, (i) the bona fide GR dimer-dependent target genes were genes involved in glucoconeogenesis in the liver and (ii) the GR monomer AP-1-dependent matrix metalloproteases and NF-kB-dependent cytokine genes, which were repressed by GCs. With this limited knowledge about GR-mediated gene regulation, drug screening programs for dissociating GR ligands were initiated that aimed to disrupt GR dimerization, but leaving GR monomer function intact with the goal to enable repression of cytokines and to avoid negative effects on glucose metabolism. However, only a few of these compounds made it into preclinical trails for topical application [34].

The last 15 years of research have revealed that for full efficacy of GCs, the GR dimer-dependent transactivation of anti-inflammatory or immune modulatory genes are necessary. In addition, the paradigm that GCs just suppress inflammation is changing to a concept that the immune system is modulated into an active mode of resolution of inflammation. Indeed, GCs are potent agents that induce the activation of anti-inflammatory monocytes/macrophages [35-37]. Important insights were also provided by a mouse knock-in model, which impaired GR dimerization, the so called $\mathrm{GR}^{\mathrm{dim}}$ mouse, a tool that is availbale to investigate the impact of the GR dimerization in vivo [38].

\section{GR mutant mouse models and GC therapy}

$\mathrm{GR}^{\mathrm{dim}}$ mice have a point mutation in the DNA binding domain of the GR and therefore reduced GR homodimerisation and, subsquently, reduced GRE binding capacity [26, $38,39]$. In contrast to the complete knockout mice [13], these $\mathrm{GR}^{\mathrm{dim}}$ mice survive until adulthood, which allows their study in disease models. In an irritant skin inflammation model induced by phorbolester or experimental autoimmune encephalomyelitis, a mouse model for multiple sclerosis, $\mathrm{GR}^{\mathrm{dim}}$ mice respond effectively to $\mathrm{GC}$ treatment, indicating that GR monomer action might be sufficient to reduce inflammation [40, 41]. In contrast, in most other inflammatory models tested, like lipopolysaccharide (LPS)-, tumor necrosis factor $\alpha$ (TNF $\alpha$ )-, and cecal ligation and puncture (CLP)-induced systemic inflammation, mice with impaired GR dimerization $\left(\mathrm{GR}^{\mathrm{dim}}\right)$ were highly susceptible to inflammation, had elevated cytokines, dysregulated metabolic pathways, and impaired thermoregulation [42]. This demonstrates that the dimerization of the GR is crucial for immune modulatory actions of endogenous GCs. Furthermore, GR ${ }^{\text {dim }}$ mice treated with exogenous GCs showed impaired anti-inflammatory response in a variety of inflammatory models: acute lung injury [43], rheumatoid arthritis [44], contact allergy [45], and allergic airway inflammation [46]. All these models again emphasize that the GC (endogenous or exogenous) activated GR dimer has substantial 
impact on the modulation of inflammation. GC activation of the GR was hypothesized to counteract inflammation. However, in inflammatory mouse models, it was shown that the GR dimer in synergy with pro-inflammatory signaling induced crucial genes that led to the resolution of inflammation: sphingosinekinase 1 [43], metallothionein1 and $2[47,48]$, and Serpin A3 [49]. This reveals that both anti-inflammatory and proinflammatory actions work together to resolve inflammation. Resistance to GC treatment in GR SUMOylation (a posttranslational modification) mutant mice during skin inflammation due to reduced co-repressor recruitment further contribute to the understanding of GC binding to GR actions [50,51]. Furthermore, mice with a mutation in the most active isoform of the GR (C3), where the GR is activated by endogenous GCs through the activation of the HPA axis during endotoxemia, are hypersensitive to LPSinduced systemic inflammation [52]. Thus, by studying mutant mice with an impaired GR dimerization in a variety of inflammatory models, novel molecular mechanims of the GR were discovered, which shows that the old classical dogma "GR monomer mediates only beneficial effects while the dimer mediates only side effects" does not hold true (Fig. 3). This explains to a major extent why the use of selective glucocorticoid receptor agonists (SEGRAs) as dissociating ligands failed in the clinics.

One way to improve GC therapy would be to identify the GC-mediated GR action in specific cell types that are necessary and sufficient for a whole body response. Valuable insights have been gained from cell type-specific conditional GR knockout mice, targeting the GR in various cell types, like myeloid cells and brain, muscle, or bone cells. We will mainly focus here on the GR-targeted deletion with the help of the Cre/loxP system in immune cells and impact during inflammation. Deletion of the GR in myeloid cells (macrophages, monocytes, and granulocytes) was achieved by crossing the Lysozyme 2 Cre recombinase (LysMCre) knock-in mice that were crossed with mice carrying flanking loxP alleles (GRflox) [45]. This led to an almost untouched GR expression,

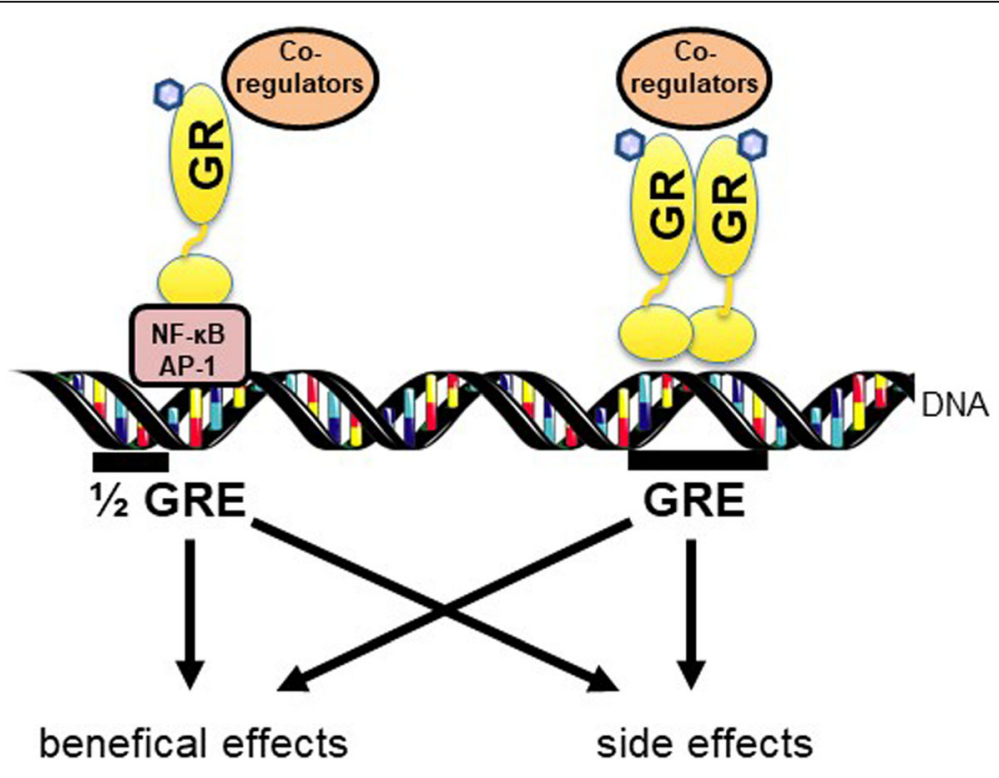

Fig. 3 The classical dogma that the glucocorticoid receptor (GR) monomer by interaction with proinflammatory transcription factors with AP-1, NF-kB, or half glucocorticoid response elements (1/2 GRE) mediate beneficial effects while the dimer mediates side effects by direct binding to GREs does not hold true. The GR dimer is also important to mediate beneficial effects and the monomer side effects 
except in cells of the myeloid lineage, in which the Lyz2 gene was active, and cre recombinase recombined the GRflox locus to a GR knockout allele. In vivo experiments with $\mathrm{GR}^{\mathrm{LysMCre}}$ mice revealed that the GC activation of GR is crucial in LPS-induced systemic inflammation [53, 54], dextran sodium sulfate (DSS)-induced colitis [55], and myocardial infarction [56] to reduce inflammation. The exogenous GC treatment is mediated through the GR in myeloid cells in models of acute lung injury [43] and contact hypersensitivity [45] to mediate anti-inflammatory effects. All these studies show that the GC activation of the GR in myeloid cells is of major importance for the immune modulatory outcome during inflammation. Intriguingly, not only is the GC activation/binding of the GR in immune cells crucial for a proper response, as discussed above, but even in non-immune cells (such as fibroblasts), the GC binding the GR indirectly triggers the resolution of inflammation by influencing immune cell polarization and, hence, outcome during inflammation $[44,57]$.

In the following sections, we will focus on the effects of impaired GR dimerization in mutant mice ( $G R^{\mathrm{dim}}$ mice) and its impact on organ function during critical illnessassociated systemic inflammation to demonstrate the impact of a functional GR that is activated by endogenous GCs.

\section{Effects of an impairment of GR dimerization on organ function in different mouse models}

The effects of systemic inflammation, i.e., resuscitated CLP-induced septic shock, on glucose metabolism in mice have been described previously [58]. Interesting preliminary results with LPS-induced systemic inflammation and the blood glucose levels in $\mathrm{GR}^{\mathrm{dim}}$ mice led to additional studies (unpublished). When $\mathrm{GR}^{\mathrm{dim}}$ [38] and wild-type contol mice $\left(\mathrm{GR}^{+/+}\right)$challenged with LPS without subsquent hemodynamic monitoring, ventilatory support, nor temperature control, the $\mathrm{GR}^{\mathrm{dim}}$ mice exhibited low glycemic levels, which coincides with severe hypothermia in contrast to $\mathrm{GR}^{+/+}$(Fig. 4a). Reduced core temperature and malaise was already described in a previous study of $\mathrm{GR}^{\mathrm{dim}}$ LPS-

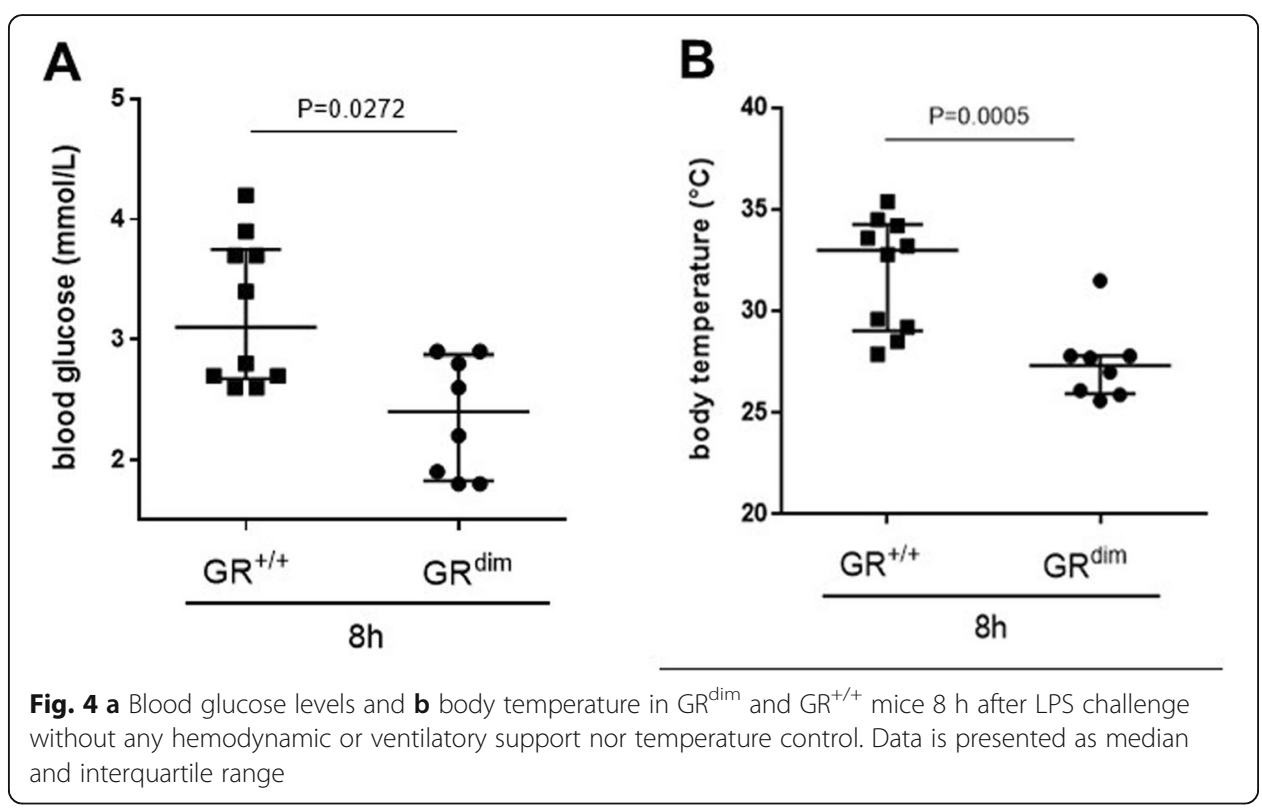


induced inflammation without intensiv care management (Fig. 4b, [59]). In order to study the effects of LPS challenge in GR $^{\mathrm{dim}}$ mice and control for hemodynamics, lung function, and temperature, the mice were placed in a mouse intensive care unit (MICU). Although the focus was to study the effects of core temperature and the relation to blood glucose levels in this setup, it was detected that the GR dimer significantly contributed to hemodynamic instability during LPS-induced inflammation. The GR ${ }^{\text {dim }}$ mice, after the LPS challenge, required significantly higher doses of norepinephrine (NA) to maintain mean arterial pressure above $55 \mathrm{mmHg}$ compared to $\mathrm{GR}^{+/+}$mice [60]. These results indicate an important role for the GR dimer in regulating hemodynamic stability in LPS-induced systemic inflammation. In septic shock patients with systemic inflammation and severe hemodynamic instability, supplementation of hydrocortisone led to increased hemodynamic stability and a reduced need for vasopressors [61]. This beneficial effect of GCs on hemodynamic stability in severe septic shock in patients might be explained by stimulation of endothelial GRs [62] and an attenuation of the cytokine-mediated downregulation of vasoconstrictive receptors, such as $\alpha_{1}$-adrenergic receptors or the $V_{1 \mathrm{~A}}$ receptor [63]. Goodwin et al. studied mice with an endothelial-specific GR deletion and showed significantly more hemodynamic instability, which was accompanied by higher nitric oxide (NO) levels compared with controls [62]. It is well established that NO plays an important pathophysiological role in sepsis with both, direct and indirect deleterious as well as beneficial effects [64]. In patients, NO has well-known vasodilatory effects [65]. Thus, the higher NO levels in mice with an endothelial cell-specific GR deletion as reported by Goodwin most likely contributed to the hemodynamic instability in these animals. Although vascularspecific effects of an ubiquitous impairment of GR dimerization have not been examined while studying $\mathrm{GR}^{\mathrm{dim}}$ mice after LPS-challenge, it is likely that the increased hemodynamic instability in $\mathrm{GR}^{\mathrm{dim}}$ mice has been, at least in part, meditated via a NOinduced vasodilation [62]. In summary, these results demonstrate an important role for endogenous GCs mediated GR dimerization in maintaining hemodynamic stability during experimental systemic inflammation induced by LPS, with mechanisms other than solely endothelial GR function.

It is well-accepted clinical practice to treat asthma and chronic obstructive pulmonary disease (COPD) with synthetic GCs to reduce local and systemic inflammation [66-68]. Although approximately $20 \%$ of patients with ARDS receive synthetic GCs [69], there is no real evidence yet of its beneficial effects. Clearly, synthetic GCs may accelerate the resolution of respiratory failure, but their side effects have to be taken into account. Furthermore, there is an increased risk of mortality in patients when synthetic GCs are used >14 days after the onset of ARDS [70]. Therefore, GCs should probably not be initiated after 2 weeks of the onset of ARDS because of the uncertain risk-to-benefit ratio. On the other hand, GCs inhibit fibroblast proliferation and collagen deposition, providing the rationale for synthetic GC treatment in non-resolving ARDS with the goal of preventing progression to fibroproliferative changes later in the course of the disease [71, 72].

The lack of clarity of the effects of GC treatment in lung injury may also be related to different effects and biology of GR function. A mouse model with a total GR knockout results in lethality shortly after birth due to respiratory failure, elevated ACTH level, elevated corticosterone levels, and reduced expression of gluconeogenetic 
enzymes [13]. Furthermore, lung function is in part maintained through the GR in airway epithelial cells [73] and mesenchymal GR facilitates the development of the respiratory system in mice [74]. This emphasizes that endogenous GCs acting through the GR are critical for maturation and development of lung function.

In general, GR downregulation is reported to be associated with organ dysfunction in humans and different animal models, in particular in the liver [75], the heart [76], and the lung [77]. Vice versa, in swine with pre-existing coronary artery disease that underwent hemorrhagic shock (HS) and resuscitation, treatment with sodium thiosulfate $\left(\mathrm{Na}_{2} \mathrm{~S}_{2} \mathrm{O}_{3}\right)$ during the first $24 \mathrm{~h}$ of resuscitation attenuated the impairment of lung mechanics and gas exchange, which coincided with higher lung tissue GR expression (as assessed by western blotting and immunohistochemistry, Fig. 5a, [78]). Existing studies so far showed that the GR is transcriptionally more active when phosphorylated on Serine 211 (pSer211), in part due to a conformational change and increased recruitment to GRE-containing promoters [79]. The GR phosphorylation site Serine 203 (pSer203) is contained within the cytoplasmic fraction of the cell and fails to bind GRE-containing promoters, suggesting that pGRSer203 is a transcriptionally inactive form of the GR [79]. Therefore, two different phosphorylation sites of the GR (Serine 211 and 203) were investigated in lung tissue of swine with pre-existing coronary artery disease that underwent HS and resuscitation. While pGRSer203 remained unaltered (Fig. 5b), GRSer211 was significantly decreased in lung tissue of thiosulfate-treated animals (Fig. 5), suggesting a less active GR signaling. However, for GR target genes like

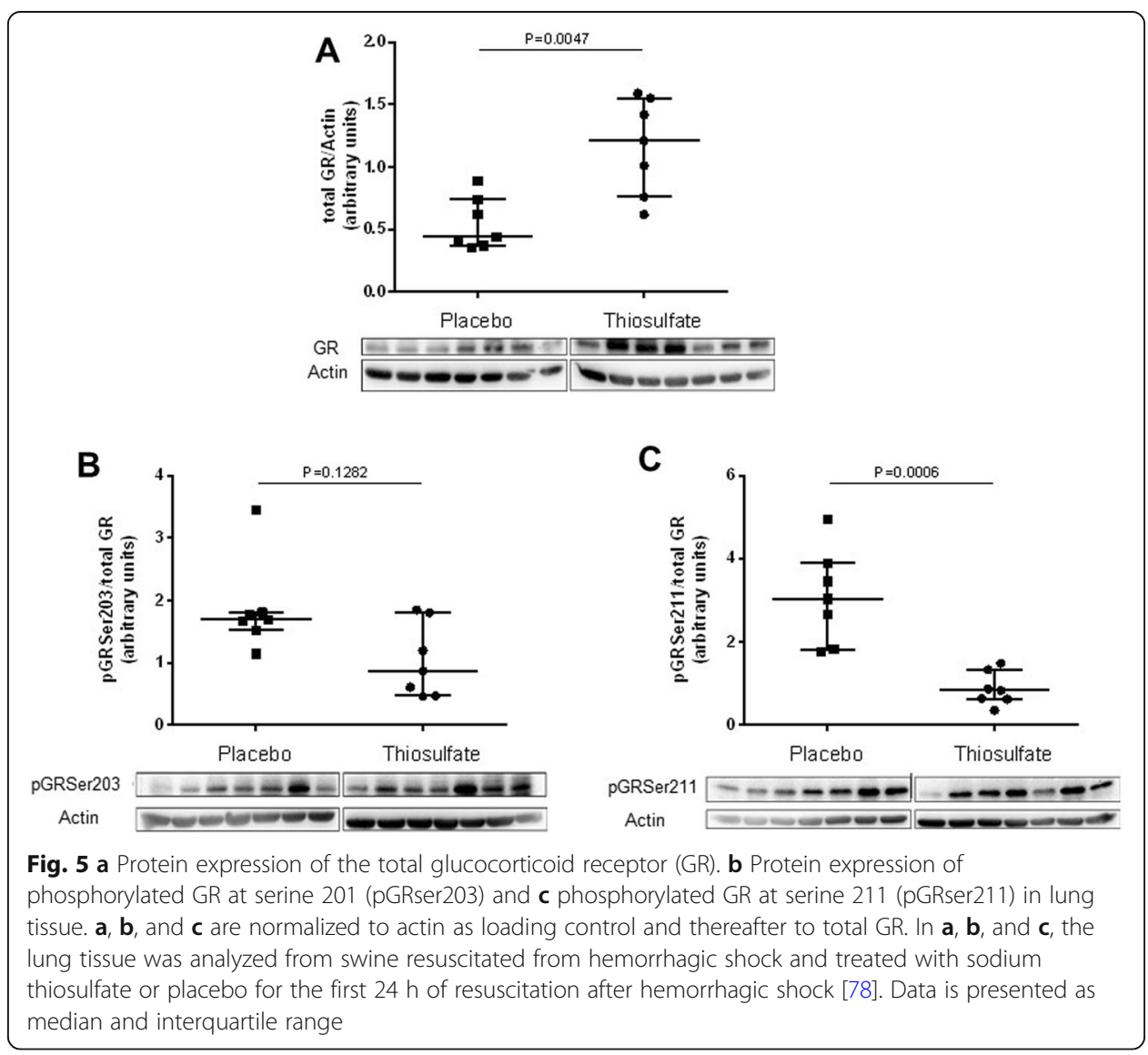


glucocorticoid-induced leucine zipper (GILZ), mitogen-activated protein kinase phosphatase 1 (MKP1), or sphingosine kinase 1 (SPHK1, known to resolve the inflammatory response), similar expression were found in the lungs of thiosulfate-treated animals. This suggests that the Serine 211 phosphorylation site of the GR might not always indicate a higher activation level of the GR at this later time point ( $72 \mathrm{~h}$ after resuscitation) as it was already shown in neuronal cells [79].

\section{Conclusion}

Basic research studies have shown that impaired glucocorticoid receptor (GR) dimerization increases mortality in lipopolysaccharide (LPS) and cecal-ligation-andpuncture (CLP)-induced inflammation and aggravates circulatory and pulmonary dysfunction after LPS-induced systemic inflammation. Attenuating GR dimerization results in resistance to exogenous glucocorticoids (GCs) to ameliorate acute lung injury (ALI). These results may indicate a role of the GR dimer to affect organ function in states of systemic inflammation and reveal some crucial immunmodulatory target genes. In addition, with the help of mutant mouse models lacking the GR in different cells and/ or tissues, the importance of GR action may be dissceted to reveal basic mechanisms.

\footnotetext{
Abbreviations

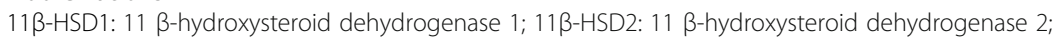
ACTH: Adrenocorticotropic hormone; ALI: Acute lung injury; ARDS: Acute respiratory distress syndrome; CBG: Corticosteroid-binding globulin; CIRCI: Critical illness-related corticosteroid insufficiency; CLP: Cecal ligation and puncture; COPD: Chronic obstructive pulmonary disease; CRF: Corticotropin-releasing factor; DSS: Dextran sodium sulfate; GBS: Glucocorticoid receptor binding sites; GCs: Glucocorticoids; GILZ: Glucocorticoid-induced leucine zipper; GR: Glucocorticoid receptor; GR ${ }^{\text {dim }}$ : Glucocorticoid receptor dimerization; GRE: Glucocorticoid receptor response element; HPA: Hypothalamic-pituitary-adrenal; HS: Hemorrhagic shock; Hsp: Heat shock proteins;

LPS: Lipopolysaccharide; MICU: Mouse intensive care unit; MKP1: Mitogen-activated protein kinase phosphatase 1; MR: Mineralocorticoid receptor; NA: Norepinephrine; $\mathrm{Na}_{2} \mathrm{~S}_{2} \mathrm{O}_{3}$ : Sodium thiosulfate; NO: Nitric oxide;

POMC: Proopiomelanocortin; SEGRAs: Selective glucocorticoid receptor agonists; SPHK1: Sphingosine kinase 1;

TNFa: Tumor necrosis factor a
}

Acknowledgments

Not applicable.

\section{About this supplement}

This article has been published as part of Intensive Care Medicine Experimental Volume 8 Supplement 1, 2020: Proceedings from the Fourth International Symposium on Acute Pulmonary Injury and Translation Research (INSPIRES IV). The full contents of the supplement are available at https://icm-experimental.springeropen.com/articles/ supplements/volume-8-supplement-1.

\section{Authors' contributions}

MW and SV drafted the manuscript, figures, and tables. JP, TM, and OM performed the experiments, analyzed the tissue, and evaluated the results described in some of the main papers cited in this review. PR, JT, and OM critically reviewed and edited the manuscript. All authors were involved in the acquisition and interpretation of data and read and approved the final version.

\section{Funding}

Publication costs are funded by the Deutsche Forschungsgemeinschaft (DFG, German Research Foundation) —Project ID INST 40/600-1_Collaborative Research Center (CRC) Projektnummer 251293561 - SFB 1149 to MW and SV. PR and JPT received funding from the Deutsche Forschungsgemeinschaft (DFG, German Research Foundation) Collaborative Research Center (CRC) Projektnummer 251293561 - SFB 1149 and GRK 2203.

Availability of data and materials

Data sharing is not applicable to this article as no datasets were generated or analyzed during the current study.

Ethics approval and consent to participate

Not applicable

Consent for publication

Not applicable 


\section{Competing interests}

The authors declare that they have no competing interests.

\section{Author details}

${ }^{1}$ Institute for Anesthesiological Pathophysiology and Process Engineering, University Hospital Ulm, Ulm, Germany. ${ }^{2}$ Department of Anesthesia, University Hospital UIm, UIm, Germany. ${ }^{3}$ Institute of Comparative Molecular Endocrinology (CME), Ulm University, Ulm, Germany.

Received: 14 July 2020 Accepted: 16 July 2020

Published: 18 December 2020

\section{References}

1. Ps H, Ec K (1949) The effect of a hormone of the adrenal cortex (17-hydroxy-11-dehydrocorticosterone; compound E) and of pituitary adrenocorticotropic hormone on rheumatoid arthritis. Proc Staff Meet Mayo Clin 24(8):181-197

2. Burns CM (2016) The history of cortisone discovery and development. Rheum Dis Clin N Am 42(1):1-14 vii

3. Vermes I, Beishuizen A (2001) The hypothalamic-pituitary-adrenal response to critical illness. Best Pract Res Clin Endocrinol Metab 15(4):495-511

4. Boonen E, Vervenne H, Meersseman P, Andrew R, Mortier L, Declercq PE et al (2013) Reduced cortisol metabolism during critical illness. N Engl J Med 368(16):1477-1488

5. Cohen J, Venkatesh B (2019) Adjunctive corticosteroid treatment in septic shock. Anesthesiology 131(2):410-419

6. Marik PE (2009) Critical illness-related corticosteroid insufficiency. Chest 135(1):181-193

7. Polito A, Sonneville R, Guidoux C, Barrett L, Viltart O, Mattot V et al (2011) Changes in CRH and ACTH synthesis during experimental and human septic shock. PLoS One 6(11):e25905

8. Sharshar T, Gray F, La Lorin de Grandmaison G, Hopkinson NS, Ross E, Dorandeu A et al (2003) Apoptosis of neurons in cardiovascular autonomic centres triggered by inducible nitric oxide synthase after death from septic shock. Lancet 362(9398):1799-1805

9. Hotta M, Baird A (1986) Differential effects of transforming growth factor type beta on the growth and function of adrenocortical cells in vitro. Proc Natl Acad Sci U S A 83(20):7795-7799

10. Jäättelä M, Ilvesmäki V, Voutilainen R, Stenman UH, Saksela E (1991) Tumor necrosis factor as a potent inhibitor of adrenocorticotropin-induced cortisol production and steroidogenic P450 enzyme gene expression in cultured human fetal adrenal cells. Endocrinology 128(1):623-629

11. Hartmann K, Koenen M, Schauer S, Wittig-Blaich S, Ahmad M, Baschant U et al (2016) Molecular actions of glucocorticoids in cartilage and bone during health, disease, and steroid therapy. Physiol Rev 96(2):409-447

12. Sher LB, Harrison JR, Adams DJ, Kream BE (2006) Impaired cortical bone acquisition and osteoblast differentiation in mice with osteoblast-targeted disruption of glucocorticoid signaling. Calcif Tissue Int 79(2):118-125

13. Cole TJ, Blendy JA, Monaghan AP, Krieglstein K, Schmid W, Aguzzi A et al (1995) Targeted disruption of the glucocorticoid receptor gene blocks adrenergic chromaffin cell development and severely retards lung maturation. Genes Dev 9(13):1608-1621

14. Rauch A, Seitz S, Baschant U, Schilling AF, Illing A, Stride B et al (2010) Glucocorticoids suppress bone formation by attenuating osteoblast differentiation via the monomeric glucocorticoid receptor. Cell Metab 11(6):517-531

15. Nussey S, Whitehead S (2001) Endocrinology: an integrated approach, Oxford

16. Papadimitriou A, Priftis KN (2009) Regulation of the hypothalamic-pituitary-adrenal axis. Neuroimmunomodulation 16(5): 265-271

17. Breuner CW, Orchinik M (2002) Plasma binding proteins as mediators of corticosteroid action in vertebrates. Endocrinol 175(1):99-112

18. Monder C, White PC (1993) 11 beta-hydroxysteroid dehydrogenase. Vitam Horm 47:187-271

19. Wake DJ, Walker BR (2004) 11 beta-hydroxysteroid dehydrogenase type 1 in obesity and the metabolic syndrome. Mol Cell Endocrinol 215(1-2):45-54

20. Hughes KA, Webster SP, Walker BR (2008) 11-Beta-hydroxysteroid dehydrogenase type 1 (11 beta-HSD1) inhibitors in type 2 diabetes mellitus and obesity. Expert Opin Investig Drugs 17(4):481-496

21. Pratt WB, Toft DO (2003) Regulation of signaling protein function and trafficking by the hsp90/hsp70-based chaperone machinery. Exp Biol Med (Maywood) 228(2):111-133

22. Pratt WB (1993) The role of heat shock proteins in regulating the function, folding, and trafficking of the glucocorticoid receptor. J Biol Chem 268(29):21455-21458

23. Grad I, Picard D (2007) The glucocorticoid responses are shaped by molecular chaperones. Mol Cell Endocrinol 275(1-2): 2-12

24. Beato M, Herrlich P, Schütz G (1995) Steroid hormone receptors: many actors in search of a plot. Cell 83(6):851-857

25. John S, Sabo PJ, Thurman RE, Sung M-H, Biddie SC, Johnson TA et al (2011) Chromatin accessibility pre-determines glucocorticoid receptor binding patterns. Nat Genet 43(3):264-268

26. Lim H-W, Uhlenhaut NH, Rauch A, Weiner J, Hübner S, Hübner N et al (2015) Genomic redistribution of GR monomers and dimers mediates transcriptional response to exogenous glucocorticoid in vivo. Genome Res 25(6):836-844

27. Biddie SC, John S, Sabo PJ, Thurman RE, Johnson TA, Schiltz RL et al (2011) Transcription factor AP1 potentiates chromatin accessibility and glucocorticoid receptor binding. Mol Cell 43(1):145-155

28. John S, Sabo PJ, Johnson TA, Sung M-H, Biddie SC, Lightman SL et al (2008) Interaction of the glucocorticoid receptor with the chromatin landscape. Mol Cell 29(5):611-624

29. Oh K-S, Patel H, Gottschalk RA, Lee WS, Baek S, Fraser IDC et al (2017) Anti-inflammatory chromatinscape suggests alternative mechanisms of glucocorticoid receptor action. Immunity 47(2):298-309.e5

30. Uhlenhaut NH, Barish GD, Yu RT, Downes M, Karunasiri M, Liddle C et al (2013) Insights into negative regulation by the glucocorticoid receptor from genome-wide profiling of inflammatory cistromes. Mol Cell 49(1):158-171

31. Schiller BJ, Chodankar R, Watson LC, Stallcup MR, Yamamoto KR (2014) Glucocorticoid receptor binds half sites as a monomer and regulates specific target genes. Genome Biol 15(7):418 
32. Presman DM, Ganguly S, Schiltz RL, Johnson TA, Karpova TS, Hager GL (2016) DNA binding triggers tetramerization of the glucocorticoid receptor in live cells. Proc Natl Acad Sci U S A 113(29):8236-8241

33. Schäcke H, Hennekes H, Schottelius A, Jaroch S, Lehmann M, Schmees N et al (2002) SEGRAs: a novel class of antiinflammatory compounds. Ernst Schering Res Found Workshop 40:357-371

34. Vandevyver S, Dejager L, Tuckermann J, Libert C (2013) New insights into the anti-inflammatory mechanisms of glucocorticoids: an emerging role for glucocorticoid-receptor-mediated transactivation. Endocrinology 154(3):993-1007

35. Barczyk K, Ehrchen J, Tenbrock K, Ahlmann M, Kneidl J, Viemann D et al (2010) Glucocorticoids promote survival of antiinflammatory macrophages via stimulation of adenosine receptor A3. Blood 116(3):446-455

36. Ehrchen J, Steinmüller L, Barczyk K, Tenbrock K, Nacken W, Eisenacher M et al (2007) Glucocorticoids induce differentiation of a specifically activated, anti-inflammatory subtype of human monocytes. Blood 109(3):1265-1274

37. Ehrchen JM, Roth J, Barczyk-Kahlert K (2019) More than suppression: glucocorticoid action on monocytes and macrophages. Front Immunol 10:2028

38. Reichardt HM, Kaestner KH, Tuckermann J, Kretz O, Wessely O, Bock R et al (1998) DNA binding of the glucocorticoid receptor is not essential for survival. Cell 93(4):531-541

39. Heck S, Kullmann M, Gast A, Ponta H, Rahmsdorf HJ, Herrlich P et al (1994) A distinct modulating domain in glucocorticoid receptor monomers in the repression of activity of the transcription factor AP-1. EMBO J 13(17):40874095

40. Reichardt HM, Tuckermann JP, Göttlicher M, Vujic M, Weih F, Angel P et al (2001) Repression of inflammatory responses in the absence of DNA binding by the glucocorticoid receptor. EMBO J 20(24):7168-7173

41. Schweingruber N, Haine A, Tiede K, Karabinskaya A, van den Brandt J, Wüst S et al (2011) Liposomal encapsulation of glucocorticoids alters their mode of action in the treatment of experimental autoimmune encephalomyelitis. I Immunol 187(8):4310-4318

42. Vandevyver S, Dejager L, van Bogaert T, Kleyman A, Liu Y, Tuckermann J et al (2012) Glucocorticoid receptor dimerization induces MKP1 to protect against TNF-induced inflammation. J Clin Invest 122(6):2130-2140

43. Vettorazzi S, Bode C, Dejager L, Frappart L, Shelest E, Klaßen C et al (2015) Glucocorticoids limit acute lung inflammation in concert with inflammatory stimuli by induction of SphK1. Nat Commun 6:7796

44. Baschant U, Frappart L, Rauchhaus U, Bruns L, Reichardt HM, Kamradt T et al (2011) Glucocorticoid therapy of antigeninduced arthritis depends on the dimerized glucocorticoid receptor in T cells. Proc Natl Acad Sci U S A 108(48):1931719322

45. Tuckermann JP, Kleiman A, Moriggl R, Spanbroek R, Neumann A, Illing A et al (2007) Macrophages and neutrophils are the targets for immune suppression by glucocorticoids in contact allergy. J Clin Invest 117(5):1381-1390

46. Klaßen C, Karabinskaya A, Dejager L, Vettorazzi S, van Moorleghem J, Lühder F et al (2017) Airway epithelial cells are crucial targets of glucocorticoids in a mouse model of allergic asthma. J Immunol 199(1):48-61

47. Kasutani K, Itoh N, Kanekiyo M, Muto N, Tanaka K (1998) Requirement for cooperative interaction of interleukin-6 responsive element type 2 and glucocorticoid responsive element in the synergistic activation of mouse metallothionein-I gene by interleukin-6 and glucocorticoid. Toxicol Appl Pharmacol 151(1):143-151

48. Itoh N, Kasutani K, Muto N, Otaki N, Kimura M, Tanaka K (1996) Blocking effect of anti-mouse interleukin-6 monoclonal antibody and glucocorticoid receptor antagonist, RU38486, on metallothionein-inducing activity of serum from lipopolysaccharide-treated mice. Toxicology 112(1):29-36

49. Lannan EA, Galliher-Beckley AJ, Scoltock AB, Cidlowski JA (2012) Proinflammatory actions of glucocorticoids: glucocorticoids and TNFa coregulate gene expression in vitro and in vivo. Endocrinology 153(8):3701-3712

50. Hua G, Ganti KP, Chambon P (2016) Glucocorticoid-induced tethered transrepression requires SUMOylation of GR and formation of a SUMO-SMRT/NCOR1-HDAC3 repressing complex. Proc Natl Acad Sci U S A 113(5):E635-E643

51. Hua G, Paulen L, Chambon P (2016) GR SUMOylation and formation of an SUMO-SMRT/NCoR1-HDAC3 repressing complex is mandatory for GC-induced IR nGRE-mediated transrepression. Proc Natl Acad Sci U S A 113(5):E626-E634

52. Oakley RH, Ramamoorthy S, Foley JF, Busada JT, Lu NZ, Cidlowski JA (2018) Glucocorticoid receptor isoform-specific regulation of development, circadian rhythm, and inflammation in mice. FASEB J 32(10):5258-5271

53. Bhattacharyya S, Brown DE, Brewer JA, Vogt SK, Muglia $\amalg$ (2007) Macrophage glucocorticoid receptors regulate Toll-like receptor 4-mediated inflammatory responses by selective inhibition of p38 MAP kinase. Blood 109(10):4313-4319

54. Kleiman A, Hübner S, Parkitna R, Jan M, Neumann A, Hofer S, Weigand MA et al (2012) Glucocorticoid receptor dimerization is required for survival in septic shock via suppression of interleukin-1 in macrophages. FASEB J 26(2):722729

55. Meers GK, Bohnenberger H, Reichardt HM, Lühder F, Reichardt SD (2018) Impaired resolution of DSS-induced colitis in mice lacking the glucocorticoid receptor in myeloid cells. PLoS One 13(1):e0190846

56. Galuppo P, Vettorazzi S, Hövelmann J, Scholz C-J, Tuckermann JP, Bauersachs J et al (2017) The glucocorticoid receptor in monocyte-derived macrophages is critical for cardiac infarct repair and remodeling. FASEB J 31(11):5122-5132

57. Gerber G, Cyrot B (1991) Nonmonotonic resistivity transitions in granular superconducting ceramics. Phys Rev B Condens Matter 43(16):12935-12942

58. Albuszies G, Radermacher P, Vogt J, Wachter U, Weber S, Schoaff M et al (2005) Effect of increased cardiac output on hepatic and intestinal microcirculatory blood flow, oxygenation, and metabolism in hyperdynamic murine septic shock. Crit Care Med 33(10):2332-2338

59. Silverman MN, Mukhopadhyay P, Belyavskaya E, Tonelli LH, Revenis BD, Doran JH et al (2013) Glucocorticoid receptor dimerization is required for proper recovery of LPS-induced inflammation, sickness behavior and metabolism in mice. Mol Psychiatry 18(9):1006-1017

60. Wepler M, Preuss JM, Merz T, Hartmann C, Wachter U, McCook O et al (2019) Impaired glucocorticoid receptor dimerization aggravates LPS-induced circulatory and pulmonary dysfunction. Front Immunol 10:3152

61. Keh D, Boehnke T, Weber-Cartens S, Schulz C, Ahlers O, Bercker S et al (2003) Immunologic and hemodynamic effects of "low-dose" hydrocortisone in septic shock: a double-blind, randomized, placebo-controlled, crossover study. Am J Respir Crit Care Med 167(4):512-520

62. Goodwin JE, Feng Y, Velazquez H, Sessa WC (2013) Endothelial glucocorticoid receptor is required for protection against sepsis. Proc Natl Acad Sci U S A 110(1):306-311 
63. Burgdorff A-M, Bucher M, Schumann J (2018) Vasoplegia in patients with sepsis and septic shock: pathways and mechanisms. J Int Med Res 46(4):1303-1310

64. Hauser B, Bracht H, Matejovic M, Radermacher P, Venkatesh B (2005) Nitric oxide synthase inhibition in sepsis? Lessons learned from large-animal studies. Anesth Analg 101(2):488-498

65. Landry DW, Oliver JA (2001) The pathogenesis of vasodilatory shock. N Engl J Med 345(8):588-595

66. Riley CM, Sciurba FC (2019) Diagnosis and outpatient management of chronic obstructive pulmonary disease: a review. JAMA 321(8):786-797

67. Williams DM (2018) Clinical pharmacology of corticosteroids. Respir Care 63(6):655-670

68. Sobieraj DM, Weeda ER, Nguyen E, Coleman Cl, White CM, Lazarus SC et al (2018) Association of inhaled corticosteroids and long-acting $\beta$-agonists as controller and quick relief therapy with exacerbations and symptom control in persistent asthma: a systematic review and meta-analysis. JAMA 319(14):1485-1496

69. Bellani G, Laffey JG, Pham T, Fan E, Brochard L, Esteban A et al (2016) Epidemiology, patterns of care, and mortality for patients with acute respiratory distress syndrome in intensive care units in 50 countries. JAMA 315(8):788-800

70. Matthay MA, Zemans RL, Zimmerman GA, Arabi YM, Beitler JR, Mercat A et al (2019) Acute respiratory distress syndrome. Nat Rev Dis Primers 5(1):18

71. Thompson BT (2010) Corticosteroids for ARDS. Minerva Anestesiol 76(6):441-447

72. Meduri GU, Annane D, Chrousos GP, Marik PE, Sinclair SE (2009) Activation and regulation of systemic inflammation in ARDS: rationale for prolonged glucocorticoid therapy. Chest 136(6):1631-1643

73. Manwani N, Gagnon S, Post M, Joza S, Muglia L, Cornejo S et al (2010) Reduced viability of mice with lung epithelialspecific knockout of glucocorticoid receptor. Am J Respir Cell Mol Biol 43(5):599-606

74. Habermehl D, Parkitna JR, Kaden S, Brügger B, Wieland F, Gröne H-J et al (2011) Glucocorticoid activity during lung maturation is essential in mesenchymal and less in alveolar epithelial cells. Mol Endocrinol 25(8):1280-1288

75. Jenniskens M, Weckx R, Dufour T, Vander Perre S, Pauwels L, Derde S et al (2018) The hepatic glucocorticoid receptor is crucial for cortisol homeostasis and sepsis survival in humans and male mice. Endocrinology 159(7):2790-2802

76. Merz T, Denoix N, Wigger D, Waller C, Wepler M, Vettorazzi S et al (2020) The role of glucocorticoid receptor and oxytocin receptor in the septic heart in a clinically relevant, resuscitated porcine model with underlying atherosclerosis. Front Endocrinol (Lausanne) 11:299

77. Koulouras VP, Li R, Chen L, Hedenstierna GG (2011) Effects of inhaled carbon monoxide and glucocorticoids in porcine endotoxin sepsis. Int J Clin Exp Med 4(1):53-66

78. Datzmann T, Hoffmann A, McCook O, Merz T, Wachter U, Preuss J et al (2019) Effects of sodium thiosulfate $\left(\mathrm{Na}_{2} \mathrm{~S}_{2} \mathrm{O}_{3}\right)$ during resuscitation from hemorrhagic shock in swine with preexisting atherosclerosis. Pharmacol Res 151:104536

79. Galliher-Beckley AJ, Cidlowski JA (2009) Emerging roles of glucocorticoid receptor phosphorylation in modulating glucocorticoid hormone action in health and disease. IUBMB Life 61(10):979-986

\section{Publisher's Note}

Springer Nature remains neutral with regard to jurisdictional claims in published maps and institutional affiliations.

\section{Submit your manuscript to a SpringerOpen ${ }^{\circ}$ journal and benefit from:}

- Convenient online submission

- Rigorous peer review

- Open access: articles freely available online

- High visibility within the field

- Retaining the copyright to your article

Submit your next manuscript at $\boldsymbol{\nabla}$ springeropen.com 